\title{
Association of Apolipoprotein A5 Gene - 1131T $>$ C Polymorphism with the Risk of Metabolic Syndrome in Korean Subjects
}

\author{
Kwang Hoon Song, Seongwon Cha, Sung-Gon Yu, Hyunjoo Yu, Soo A. Oh, and Nam-Sik Kang \\ Division of Constitutional Medicine Research, and Herbal Medicine Research Division, Korea Institute of Oriental Medicine (KIOM), \\ 483 Expo-ro, Yuseong-gu, Daejeon 305-811, Republic of Korea
}

Correspondence should be addressed to Kwang Hoon Song; ksong@kiom.re.kr

Received 20 August 2012; Accepted 26 December 2012

Academic Editor: M. Ilyas Kamboh

Copyright (C) 2013 Kwang Hoon Song et al. This is an open access article distributed under the Creative Commons Attribution License, which permits unrestricted use, distribution, and reproduction in any medium, provided the original work is properly cited.

\begin{abstract}
We assessed the associations between the APOA5 -1131T $>\mathrm{C}$ polymorphism and lipid parameters and other risk factors of the metabolic syndrome in Korean subjects. A total of 2,901 participants from 20 oriental medical hospitals in Korea were enrolled between 2006 and 2011. According to the modified National Cholesterol Education Program Adult Treatment Panel III definitions, subjects were classified into the metabolic syndrome group and control group. The APOA5 $-1131 \mathrm{~T}>\mathrm{C}$ genotype was significantly associated with serum high-density lipoprotein cholesterol levels (effect $=-1.700 \mathrm{mg} / \mathrm{dL}, P=6.550$-E07) in the total study population after adjustment for differences in age and gender. The association of the APOA5 -1131T $>\mathrm{C}$ genotype with serum logtransformed triglyceride was also significant in an additive genetic model (effect $=0.056 \mathrm{mg} / \mathrm{dL}, P=2.286 \mathrm{E}-19$ ). After adjustment for age and gender, we determined that the odds ratio for the occurrence of the metabolic syndrome was 1.322 for $\mathrm{C}$-allele carriers in the additive model (95\% CI $=[1.165-1.501], P=1.48 \mathrm{E}-05)$. In the current study, we demonstrated that the APOA5 $-1131 \mathrm{~T}>\mathrm{C}$ polymorphism is associated with the metabolic syndrome because of its remarkable effect on serum triglyceride levels in Korean subjects.
\end{abstract}

\section{Introduction}

Metabolic syndrome (MS) is defined by the clustering of cardiovascular risk factors such as abdominal obesity, dyslipidemia, hypertension, and hyperglycemia and is significantly associated with increased risk of developing diabetes and cardiovascular disease $[1,2]$. The prevalence of this syndrome has significantly increased in Koreans in the past decade and affected an estimated $31.3 \%$ of the population in 2007 [3]. Susceptibility to MS is influenced by the imbalance between caloric intake and expenditure, and by genetic factors [46]. Moreover, genome-wide scans have revealed various chromosomal regions with suggestive linkage to MS [79]. Recent Genome-Wide Association Study (GWAS) results from seven studies participating in the single nucleotide polymorphisms Typing for Association with Multiple Phenotypes from Existing Epidemiologic Data Consortium revealed that genetic effects on lipid levels were pronounced and that genes with variants influencing MS per se included LPL, CETP, and the APOA-cluster (APOA5, ZNF259, and BUD13), which are known to play an important role in lipid metabolism [10].

The gene encoding a novel member of the apolipoprotein family, human apolipoprotein A5 (APOA5), is located on chromosome 11q23 close to the APOA1-C3-A4 gene cluster. APOA5 comprises 4 exons encoding 366 amino acids and is an important determinant of plasma triglyceride (TG) levels, a major risk factor for coronary artery disease [11]. Genetic polymorphisms of APOA5 are associated with hypertriglyceridemia [11-13]. One of these APOA5 polymorphisms, $-1131 \mathrm{~T}>\mathrm{C}$ (rs662799), which is located in the APOA5 promoter region, has been associated with elevated plasma TG levels and reduced plasma high-density lipoprotein cholesterol (HDL-C) levels [14-17].

Several studies indicated an ethnic-specific association of the APOA5 -1131T>C polymorphism with MS [1822]. Therefore, we assessed the associations between APOA5 $-1131 \mathrm{~T}>\mathrm{C}$ polymorphism and lipid parameters and other risk factors of MS in Korean subjects. 


\section{Materials and Methods}

2.1. Study Population. Data were retrospectively collected from 20 oriental medical hospitals in Korea between 2006 and 2011. The current study population comprised 2,901 participants. Recruited participants were outpatients who had at least 4 visits. To avoid potential confounding of the association between the APOA5 $-1131 \mathrm{~T}>\mathrm{C}$ polymorphism and preexisting diseases subjects with a history of cardiovascular disease, hypertension, cancer, liver disease and diabetes (as recorded on case report forms) were excluded. All samples and clinical information were deposited in the databank of Sasang Constitutional Medicine (DB-SCM), which was renamed to Korea Constitution Multicenter Study (KCMS) recently, in the Korea Institute of Oriental Medicine as previously described [23]. All subjects provided written informed consent, and this study was approved by the Institutional Review Board of the Korea Institute of Oriental Medicine.

2.2. Genotyping of Single Nucleotide Polymorphism. The genotype of the APOA5 -1131 polymorphism was determined using an unlabeled oligonucleotide probe (UOP) that spans the polymorphic nucleotide [24]. The UOP was designed from a perfectly matched duplex with the $T$ allele of APOP5 -1131. Briefly, small segments of genomic sequence spanning the APOA5 polymorphic site were amplified by polymerase chain reaction (PCR) using $50 \mathrm{ng}$ of genomic DNAs as a template and a set of primers (APOA5 -1131-F1 ACTCTGAGCCCCAGGAAC, APOA5 -1131-R1 GAGTGGAGTTCAGCTTTTCC). PCR amplification was performed via a heating cycle $\left(50^{\circ} \mathrm{C}\right.$ for $2 \mathrm{~min}$ and $95^{\circ} \mathrm{C}$ for $\left.10 \mathrm{~min}\right)$, followed by an amplifying step ( 40 cycles of $95^{\circ} \mathrm{C}$ for 20 seconds, $56^{\circ} \mathrm{C}$ for 20 seconds, and $72^{\circ} \mathrm{C}$ for 20 seconds) in a model C1000 thermal cycler (Bio-Rad). The PCR product was diluted with 2 volumes of distilled water, and the diluent was mixed with 6 volumes of probe solution containing $1 \mu \mathrm{M}$ UOP, $5 \mu \mathrm{M}$ Syto 9 (Invitrogen), $12.5 \mathrm{mM}$ EDTA, and $10 \mathrm{mM}$ Tris ( $\mathrm{pH} 8.0$ ) and subsequently subjected to a thermal reaction for genotyping using a Lightcycler 2.0 and $480 \mathrm{II}$ instruments (Roche Diagnostics). The thermal reaction consisted of a denaturation step at $95^{\circ} \mathrm{C}$ for 5 seconds, an annealing step at $60^{\circ} \mathrm{C}$ for $1 \mathrm{~min}$ to allow annealing of complementary strands (UOP, APOA5 -1131-S AGCTTTTCCTCATGGGGCAAATCTCACTT), and a melting step with a gradual increase in temperature at a rate of $0.1^{\circ} \mathrm{C} /$ second until $95^{\circ} \mathrm{C}$, when fluorescence emissions were read. The genotype of each PCR product was then determined from 3 melting patterns (major homozygote, heterozygote, and minor homozygote) on the basis of the temperature where the corresponding UOP melted.

2.3. Criteria for MS. MS was defined according to the National Cholesterol Education Program Adult Treatment Panel III (NECP ATP III) guidelines, which stipulated that at least 3 of the following 5 criteria had to be met: (1) fasting blood glucose $(\mathrm{FBG}) \geq 100 \mathrm{mg} / \mathrm{dL}$, (2) $\mathrm{TG} \geq 150 \mathrm{mg} / \mathrm{dL}$, (3) HDL-C $\leq 40 \mathrm{mg} / \mathrm{dL}$ for males and $50 \mathrm{mg} / \mathrm{dL}$ for females, (4) systolic blood pressure $(\mathrm{SBP}) \geq 130 \mathrm{~mm} \mathrm{Hg}$ and/or diastolic blood pressure $(\mathrm{DBP}) \geq 85 \mathrm{~mm} \mathrm{Hg}$, and (5) central obesity with waist circumference (WC) $\geq 90 \mathrm{~cm}$ for males and $\geq 80 \mathrm{~cm}$ for females. For FBG levels, we referred to the American Diabetes Association (ADA) guidelines [25] and used a modified WC cut-off of $\geq 90 \mathrm{~cm}$ in males and $\geq 80 \mathrm{~cm}$ in females as abdominal obesity cutoff points [26].

2.4. Statistics. The quantitative variables were presented as mean \pm standard deviation. The allele frequency of the APOA5 -1131T >C polymorphism was determined by gene counting. Chi-square analysis was used to evaluate whether the APOA5 $-1131 \mathrm{~T}>\mathrm{C}$ polymorphism was in Hardy-Weinberg equilibrium in the population. For comparison of quantitative variables between subjects with MS and controls, MS risk factors (SBP, DBP, TG, WC, HDL-C, and FBG), we used Student's $t$-test. Multiple linear regression analysis was used to identify significant variables affected by the APOA5 genotype, and effect sizes (slope) were presented as changes in minor allele carrier in an additive model, adjusting for the effects of age and gender. Tests for difference of proportions were conducted to evaluate the significance of genotype subgroup proportion differences in MS criteria. To identify the association with a binary variable, for example, MS, we used logistic regression analysis. Multiple logistic regression analyses were conducted to calculate the odds ratio $(\mathrm{OR})$ of the risk of $\mathrm{MS}$ for the carriers of the minor allele of the APOA5 - 1131T $>$ C polymorphism in an additive model, adjusting the effects of age and/or gender [27]. The effect sizes (slope and OR) were estimated with their respective $95 \%$ confidence interval (CI). A $P$-value of $<0.05$ was considered statistically significant. All statistical analyses were performed using SPSS (SPSS Inc., Chicago, IL,USA; V14.0 for Windows) and R (version 2.12.0).

\section{Results}

3.1. Characteristics and Prevalence of MS in the Total Study Population. A total of 2,901 individuals (1,040 males and 1,861 females) were enrolled in this study. Major clinical parameters including age, SBP, DBP, WC, FBG, log transformed TG (LogTG), and HDL-C levels of subjects with MS and controls in the total study population and according to gender are summarized in Table 1 and Supplementary Table 1 available online at http://dx.doi.org/10.1155/2013/585134. Using the modified NECP ATP III diagnostic criteria, we detected a $34.61 \%$ prevalence of MS in the study population (33.85\% in males and $35.03 \%$ in females). The genotype distribution of the APOA5 - 1131T >C polymorphism among the 2,901 subjects analyzed was as follows: $1,404(48.40 \%)$ subjects were homozygous for the T allele (TT), 1,237 (42.64\%) subjects were heterozygous (TC), and 260 (8.96\%) subjects were homozygous for the $\mathrm{C}$ allele (CC). The minor allele (C) frequency of the APOA $-1131 \mathrm{~T}>\mathrm{C}$ polymorphism was 0.302 , and the genotype distributions did not deviate from Hardy-Weinberg equilibrium $(P>0.05)$.

3.2. Association of the APOA5 -1131T>C Genotype with Clinical Parameters of MS. To address the association and 
TABLE 1: General characteristics of the study subjects.

\begin{tabular}{|c|c|c|c|c|}
\hline Variables & $\begin{array}{c}\text { Total } \\
(2901)\end{array}$ & $\begin{array}{c}\text { MS } \\
(1004)\end{array}$ & $\begin{array}{c}\text { Control } \\
(1897)\end{array}$ & $P$ value \\
\hline Age (years) & $47.76 \pm 15.46$ & $55.45 \pm 13.66$ & $43.69 \pm 14.79$ & $1.198 E-92$ \\
\hline $\mathrm{SBP}(\mathrm{mm} \mathrm{Hg})$ & $119.91 \pm 15.66$ & $128.94 \pm 15.55$ & $115.13 \pm 13.47$ & $3.932 E-109$ \\
\hline DBP (mm Hg) & $77.04 \pm 11.16$ & $82.66 \pm 11.08$ & $74.07 \pm 10.01$ & $1.446 E-84$ \\
\hline $\mathrm{WC}(\mathrm{cm})$ & $83.91 \pm 9.76$ & $90.88 \pm 7.73$ & $80.21 \pm 8.65$ & $3.990 E-204$ \\
\hline FBG (mg/dL) & $99.05 \pm 27.42$ & $111.75 \pm 36.62$ & $92.33 \pm 17.62$ & $9.339 E-52$ \\
\hline $\log \mathrm{TG}(\mathrm{mg} / \mathrm{dL})$ & $2.03 \pm 0.24$ & $1.94 \pm 0.19$ & $2.20 \pm 0.21$ & $1.991 \mathrm{E}-192$ \\
\hline HDL-C (mg/dL) & $47.26 \pm 12.57$ & $39.78 \pm 8.61$ & $51.22 \pm 12.53$ & $1.617 E-160$ \\
\hline
\end{tabular}

Values are indicated as the mean \pm standard deviation.

$P$ value: Student's $t$-test result between MS and Control.

Abbreviations: MS: metabolic syndrome; SBP: systolic blood pressure; DBP: diastolic blood pressure; WC: waist circumference; FBG: fasting blood glucose; LogTG: log-transformed triglyceride; HDL-C: high-density lipoprotein cholesterol.

Bold indicates statistical significance $(P<0.05)$.

TABLE 2: Association of the APOA5 -1131T>C polymorphism with MS parameters in the study population.

\begin{tabular}{|c|c|c|c|c|}
\hline & Variables & TT/TC/CC & Slope (95\% CI) & $P$ value \\
\hline \multirow{8}{*}{$\begin{array}{l}\text { Total } \\
(2901)\end{array}$} & Number (\%) & $1404(48.40) / 1237(42.64) / 260(8.96)$ & - & - \\
\hline & Age (years) & $47.93 \pm 15.54 / 47.33 \pm 15.53 / 48.92 \pm 14.61$ & - & - \\
\hline & $\mathrm{SBP}(\mathrm{mm} \mathrm{Hg})$ & $119.67 \pm 15.77 / 119.69 \pm 15.58 / 122.27 \pm 15.33$ & $0.589(-0.244,1.422)$ & 0.166 \\
\hline & $\mathrm{DBP}(\mathrm{mm} \mathrm{Hg})$ & $76.88 \pm 11.37 / 76.99 \pm 11.13 / 78.20 \pm 10.10$ & $0.326(-0.282,0.934)$ & 0.264 \\
\hline & $\mathrm{WC}(\mathrm{cm})$ & $83.94 \pm 9.72 / 83.65 \pm 9.81 / 84.97 \pm 9.73$ & $0.051(-0.451,0.553)$ & 0.843 \\
\hline & $\mathrm{FBG}(\mathrm{mg} / \mathrm{dL})$ & $99.02 \pm 27.91 / 98.98 \pm 26.24 / 99.61 \pm 30.27$ & $-0.013(-1.505,1.479)$ & 0.987 \\
\hline & $\operatorname{LogTG}(\mathrm{mg} / \mathrm{dL})$ & $2.00 \pm 0.23 / 2.04 \pm 0.24 / 2.13 \pm 0.24$ & $0.056(0.044,0.069)$ & $2.286 E-19$ \\
\hline & HDL-C (mg/dL) & $48.34 \pm 12.84 / 46.69 \pm 12.43 / 44.16 \pm 10.97$ & $-1.700(-2.368,-1.031)$ & $6.550 \mathrm{E}-07$ \\
\hline \multirow{8}{*}{$\begin{array}{l}\text { MS } \\
(1004)\end{array}$} & Number (\%) & $452(15.58) / 429(14.79) / 123(4.24)$ & - & - \\
\hline & Age (years) & $55.89 \pm 13.95 / 54.92 \pm 13.68 / 55.71 \pm 12.48$ & - & - \\
\hline & SBP $(\mathrm{mm} \mathrm{Hg})$ & $129.38 \pm 16.09 / 127.77 \pm 15.48 / 131.40 \pm 13.39$ & $0.185(-1.218,1.587)$ & 0.796 \\
\hline & $\mathrm{DBP}(\mathrm{mm} \mathrm{Hg})$ & $82.73 \pm 11.38 / 82.40 \pm 11.23 / 83.30 \pm 9.33$ & $0.065(-0.941,1.071)$ & 0.899 \\
\hline & $\mathrm{WC}(\mathrm{cm})$ & $91.17 \pm 7.51 / 90.57 \pm 8.00 / 90.92 \pm 7.56$ & $-0.328(-1.018,0.362)$ & 0.351 \\
\hline & $\mathrm{FBG}(\mathrm{mg} / \mathrm{dL})$ & $112.38 \pm 37.56 / 111.68 \pm 34.69 / 109.70 \pm 39.73$ & $1.103(-4.389,2.182)$ & 0.510 \\
\hline & $\operatorname{LogTG}(\mathrm{mg} / \mathrm{dL})$ & $2.17 \pm 0.20 / 2.22 \pm 0.22 / 2.27 \pm 0.24$ & $0.046(0.028,0.065)$ & $1.457 \mathrm{E}-06$ \\
\hline & HDL-C (mg/dL) & $40.62 \pm 8.94 / 39.05 \pm 8.45 / 39.28 \pm 7.62$ & $-0.818(-1.566,-0.071)$ & 0.032 \\
\hline \multirow{8}{*}{$\begin{array}{l}\text { Control } \\
\text { (1897) }\end{array}$} & Number (\%) & $952(32.82) / 808(27.85) / 137(4.72)$ & - & - \\
\hline & Age (years) & $44.15 \pm 14.81 / 43.30 \pm 14.94 / 42.82 \pm 13.69$ & - & - \\
\hline & SBP (mm Hg) & $115.06 \pm 13.35 / 115.39 \pm 13.84 / 114.07 \pm 11.98$ & $-0.223(-1.15,0.704)$ & 0.637 \\
\hline & $\mathrm{DBP}(\mathrm{mm} \mathrm{Hg})$ & $74.10 \pm 10.26 / 74.12 \pm 9.95 / 73.63 \pm 8.47$ & $-0.205(-0.907,0.497)$ & 0.566 \\
\hline & $\mathrm{WC}(\mathrm{cm})$ & $80.50 \pm 8.71 / 79.97 \pm 8.64 / 79.63 \pm 8.26$ & $-0.519(-1.098,0.06)$ & 0.079 \\
\hline & FBG (mg/dL) & $92.67 \pm 18.83 / 92.24 \pm 16.87 / 90.55 \pm 12.42$ & $-0.822(-2.067,0.424)$ & 0.196 \\
\hline & $\log \mathrm{TG}(\mathrm{mg} / \mathrm{dL})$ & $1.92 \pm 0.19 / 1.95 \pm 0.19 / 2.02 \pm 0.18$ & $0.042(0.029,0.055)$ & $2.158 \mathrm{E}-10$ \\
\hline & $\mathrm{HDL}-\mathrm{C}(\mathrm{mg} / \mathrm{dL})$ & $52.01 \pm 12.78 / 50.75 \pm 12.30 / 48.55 \pm 11.67$ & $-1.304(-2.174,-0.435)$ & 0.003 \\
\hline
\end{tabular}

Values are indicated as the mean \pm standard deviation.

$P$ value: multiple regression analysis adjusted for age and sex (TT, TC, CC).

Abbreviations: CI: confidence interval; SBP: systolic blood pressure; DBP: diastolic blood pressure; WC: waist circumference; FBG: fasting blood glucose; LogTG: log-transformed triglyceride; HDL-C: high-density lipoprotein cholesterol.

Bold indicates statistical significance $(P<0.05)$. 
TABLE 3: The prevalence of MS risk factors according to APOA5 -1131 genotype.

\begin{tabular}{|c|c|c|c|c|c|c|}
\hline & \multirow{2}{*}{ Variables } & \multicolumn{4}{|c|}{ Number (\%) } & \multirow{2}{*}{$P$ value } \\
\hline & & TT (1404) & TC (1237) & CC (260) & Total (2901) & \\
\hline \multirow{5}{*}{$\begin{array}{l}\text { Total } \\
(2901)\end{array}$} & High FBG & $423(30.13)$ & $398(32.17)$ & $96(36.92)$ & $917(31.61)$ & 0.082 \\
\hline & Low HDL-C & $674(48.01)$ & $639(51.66)$ & $156(60.00)$ & $1469(50.64)$ & 0.001 \\
\hline & High BP & $448(31.91)$ & $411(33.23)$ & $110(42.31)$ & $969(33.40)$ & 0.005 \\
\hline & High TG & $312(22.22)$ & 345 (27.89) & $106(40.77)$ & $763(26.30)$ & $8.637 E-10$ \\
\hline & Large WC & $720(51.28)$ & $604(48.83)$ & 135 (51.92) & 1459 (50.29) & 0.389 \\
\hline \multirow{5}{*}{$\begin{array}{l}\text { Male } \\
(1040)\end{array}$} & High FBG & $178(37.55)$ & $155(33.55)$ & $44(42.31)$ & $377(36.25)$ & 0.142 \\
\hline & Low HDL-C & $177(37.34)$ & $204(44.16)$ & $52(50.00)$ & $433(41.63)$ & 0.001 \\
\hline & High BP & $181(38.19)$ & $189(40.91)$ & $46(44.23)$ & $416(40.00)$ & 0.059 \\
\hline & High TG & $141(29.75)$ & $158(34.20)$ & 49 (47.12) & $348(33.46)$ & $1.718 E-04$ \\
\hline & Large WC & $170(35.86)$ & 157 (33.98) & $44(42.31)$ & $371(35.67)$ & 0.101 \\
\hline \multirow{5}{*}{$\begin{array}{l}\text { Female } \\
(1861)\end{array}$} & High FBG & $245(26.34)$ & $243(31.35)$ & $52(33.33)$ & $540(29.02)$ & 0.294 \\
\hline & Low HDL-C & $497(53.44)$ & $435(56.13)$ & $104(66.67)$ & $1036(55.67)$ & 0.316 \\
\hline & High BP & $267(28.71)$ & $222(28.65)$ & $64(41.03)$ & $553(29.72)$ & 0.045 \\
\hline & High TG & $171(18.39)$ & $187(24.13)$ & $57(36.54)$ & $415(22.30)$ & $1.146 E-04$ \\
\hline & Large WC & $550(59.14)$ & 447 (57.68) & $91(58.33)$ & 1088 (58.46) & 0.187 \\
\hline
\end{tabular}

Values are indicated as number (\%).

$P$ value: test for difference of proportions (TT, TC, CC).

Abbreviations: MS: metabolic syndrome; FBG: fasting blood glucose; HDL-C: high-density lipoprotein cholesterol; TG: triglyceride; WC: waist circumference. Bold indicates statistical significance $(P<0.05)$.

TABLE 4: Odds ratio of MS according to carriers of the minor allele of the APOA5-1131T>C polymorphism.

\begin{tabular}{|c|c|c|c|c|c|}
\hline & Subjects & MAF & TT/TC/CC & OR $(95 \% \mathrm{CI})$ & $P$ value \\
\hline \multirow{2}{*}{ Total (2901) } & MS & 0.336 & $452 / 429 / 123$ & $1.322(1.165,1.501)$ & $1.48 E-05$ \\
\hline & Control & 0.285 & $952 / 808 / 137$ & - & \\
\hline \multirow{2}{*}{ Male (1040) } & MS & 0.352 & $151 / 154 / 47$ & $1.285(1.050,1.574)$ & 0.015 \\
\hline & Control & 0.307 & $323 / 308 / 57$ & - & \\
\hline \multirow{2}{*}{ Female (1861) } & MS & 0.327 & $301 / 275 / 76$ & $1.339(1.138,1.576)$ & $4.52 E-04$ \\
\hline & Control & 0.273 & $629 / 500 / 80$ & - & \\
\hline
\end{tabular}

Abbreviations: MS: metabolic syndrome; MAF: minor allele frequency; OR: odds ratio; CI: confidence interval.

Subjects: MS: subjects with $\geq 3$ MS risk factors; control: subjects with $<3$ MS risk factors.

$P$ value: adjusted for age and/or sex in multiple logistic regression analysis in an additive model.

Bold indicates statistical significance $(P<0.05)$.

impact of the APOA5 $-1131 \mathrm{~T}>\mathrm{C}$ polymorphism on clinical parameters of MS, we evaluated the mean values of age, SBP, DBP, WC, FBG, TG, and HDL-C of each genotype and performed multiple regression analysis using the total study population, subjects with MS, and controls. There was a significant association between serum HDL-C levels and the APOA5 -1131T>C genotype (effect $=-1.700 \mathrm{mg} / \mathrm{dL}$, $P=6.550 \mathrm{E}-07)$ in the total population after adjustment for differences in age and gender. The association of APOA5 $-1131 \mathrm{~T}>\mathrm{C}$ with serum LogTG values was also significant in an additive genetic model. The TC genotype group showed higher serum LogTG levels $(2.04 \pm 0.24 \mathrm{mg} / \mathrm{dL})$ than the TT genotype group $(2.00 \pm 0.23 \mathrm{mg} / \mathrm{dL})$, and the CC genotype group showed the highest serum LogTG levels $(2.13 \pm$ $0.24 \mathrm{mg} / \mathrm{dL}$ ). However, there were no significant differences in SBP, DBP, WC, and FBG between these genotype groups (Table 2). The $\mathrm{C}$ allele was associated with higher levels of
LogTG (MS: effect $=0.046 \mathrm{mg} / \mathrm{dL}, P=1.457 \mathrm{E}-06$; control: effect $=0.042 \mathrm{mg} / \mathrm{dL}, P=2.158 \mathrm{E}-10)$, and the minor allele had a lowering effect on the levels of HDL-C levels (MS: effect $=-0.818 \mathrm{mg} / \mathrm{dL}, P=0.032$; control: effect $=$ $-1.304 \mathrm{mg} / \mathrm{dL}, P=0.003)$.

Since it has been reported that gender has an important impact on the correlation of APOA5 with serum HDL-C and TG levels $[22,23]$, we also analyzed the data according to gender (Supplementary Table 2). In both male and female subjects, the $\mathrm{C}$ allele correlated with higher levels of TG (in male, effect $=0.061 \mathrm{mg} / \mathrm{dL}, P=1.963 \mathrm{E}-08$; in female, effect $=$ $0.053 \mathrm{mg} / \mathrm{dL}, P=3.772 \mathrm{E}-12$ ) and with lower HDL-C levels (in male, effect $=-2.102 \mathrm{mg} / \mathrm{dL}, P=3.810 \mathrm{E}-05$; in female, effect $=-1.444 \mathrm{mg} / \mathrm{dL}, P=0.001$ ) in the total population. Furthermore, the minor allele had lowering effects on HDL$\mathrm{C}$ levels only for the male controls (effect $=-2.092 \mathrm{mg} / \mathrm{dL}$, $P=0.001)$. 
3.3. Prevalence and Odds Ratio of MS according to Carriers of the Minor Allele of the APOA5-1131T >C Polymorphism. The relative frequencies of the individual risk factors of the MS in the total population and according to gender are summarized in Table 3. The prevalence of MS was $32.19 \%$ (31.86\% in males and $32.37 \%$ in females), $34.68 \%$ (33.33\% in males and $35.48 \%$ in females), and $47.31 \%$ (45.19\% in males and $48.72 \%$ in females) in subjects with the TT, TC, and CC genotype, respectively. Low HDL-C levels and large WC were the most common risk factor of MS regardless of the genotype in the total population. A high TG level was ranked the lowest priority in the frequencies of individual risk factors of MS in subjects with the TT and TC genotypes but it was significantly more prevalent in subjects with the CC genotype. Interestingly, there was a high frequency of the minor allele $(C)$ of the APOA5 -1131 polymorphism in subjects with MS (control, 0.285 versus $M S, 0.336$ ). Moreover, the minor allele $(C)$ of the APOA5 -1131 polymorphism in subjects with MS was more prevalent in females (control, 0.273 versus MS, 0.327 ) than in males (control, 0.307 versus MS, 0.352) (Table 4).

Since our findings indicated that the increase in the minor allele (C) frequency of the APOA5 -1131 polymorphism was correlated significantly with the prevalence of MS, we calculated ORs for MS according to the carriers of the minor allele of the polymorphism using logistic regression analysis in an additive model (Table 4). After adjustment for age and gender, we determined that the OR for the occurrence of MS was 1.322 for C-allele carriers (95\% CI = [1.165-1.501], $P=1.48 E-05)$. In addition, the association between the $C$ allele of the APOA5 polymorphism and MS was stable in both males $(\mathrm{OR}=1.285,95 \% \mathrm{CI}=[1.050-1.574], P=0.015)$ and females $(\mathrm{OR}=1.339,95 \% \mathrm{CI}=[1.138-1.576], P=4.52 E-04)$ after adjustment for age.

\section{Discussion}

Naturally occurring polymorphisms of APOA5 are associated with hypertriglyceridemia, which is a component of MS [6, $11,18,23]$. Among the APOA5 polymorphisms, $-1131 \mathrm{~T}>\mathrm{C}$ is a regulatory variant of $A P O A 5$ that is predominantly associated with TG levels; a recent study documented the strong association of the $-1131 \mathrm{~T}>\mathrm{C}$ polymorphism with serum TG levels in a dose-dependent manner [11, 28]. In addition, a significant dose-dependent association has been reported between the APOA $5-1131 \mathrm{~T}>\mathrm{C}$ polymorphism and the risk of coronary heart disease in an analogous dosedependent manner, with about an $18 \%$ higher risk per $\mathrm{C}$ allele, providing evidence for a causal association between TG-mediated pathways and coronary heart disease [28].

In this study, we investigated the roles of the APOA5 $-1131 \mathrm{~T}>\mathrm{C}$ polymorphism in serum lipid levels and the association of the prevalence of MS in the Korean population. The APOA5 $-1131 \mathrm{~T}>\mathrm{C}$ polymorphism was found to be significantly associated with serum TG and HDL-C levels (Table 2, Supplementary Table 2 ), reemphasizing that it has a significant impact on both serum HDL-C and TG levels. Low HDL-C levels are associated with high blood TG levels. It has been suggested that deficiency of APOA5 delays TG hydrolysis and reduces the availability of surface components of TG-rich lipoproteins, which contribute to HDL-C formation, thereby leading to decreased formation of HDL-C $[17,29]$. Since the APOA5 - 1131T $>C$ polymorphism is located in the promoter region of $A P O A 5$, it may alter the $A P O A 5$ expression and impair its function, and cooperative effects between APOA5 polymorphisms cannot be excluded. Moreover, results from in vitro studies suggested that haplotypes carrying rare alleles of APOA5 were associated with about $50 \%$ lower gene expression than wild-type haplotype [28].

The minor allele (C) frequency of APOA5 -1131 of 0.302 in our study population was similar to the frequency previously reported in other Korean subjects [30, 31]. However, we found that there was a significant difference in the frequency of the minor allele (C) of the APOA5 -1131 polymorphism in subjects with MS. Analysis of the overall sample indicated that the mean value in subjects with the APOA5 -1131CC genotype $(164.42 \pm 126.22 \mathrm{mg} / \mathrm{dL})$ met the MS criteria for high TG, while subjects with the TT and TC genotypes did not (114.58 \pm 66.55 and $128.97 \pm$ $82.54 \mathrm{mg} / \mathrm{dL}$, respectively). The differences in the prevalence of MS according to the APOA5 -1131 genotype suggest that the increased frequency of the minor allele of the APOA5 $-1131 \mathrm{~T}>\mathrm{C}$ polymorphism may function as a significant risk factor of MS susceptibility. Furthermore, it should be noted that we observed that subjects with the APOA5 -1131CC genotype showed higher ranking of the "high TG" parameter compared to subjects with the other genotypes, suggesting that the C-allele (and in particular the CC genotype) could be a risk factor for MS.

Gender-specific influences may interact with the APOA5 $-1131 \mathrm{~T}>\mathrm{C}$ polymorphism to modulate TG and HDL-C levels; (1) $\mathrm{C}$ carriers had a higher TG levels and lower HDL$\mathrm{C}$ levels in males than females, (2) the effect of the APOA5 $-1131 \mathrm{~T}>\mathrm{C}$ polymorphism on TG levels was pronounced in the MS group than in the control group of males, and (3) a lower HDL-C levels was only significant in the control group of males.

The $\mathrm{C}$ allele of the APOA5 -1131 polymorphism was significantly associated with an increased risk of MS in a multiple logistic regression analysis. In agreement with previous reports, we also found that the susceptibility to develop MS was higher in subjects with the APOA5 -1131CC genotype than in those with the TT and TC genotypes, which is indicative of an effect of this polymorphism on serum TG levels. The present study not only discloses the exceptionally higher prevalence of MS in APOA5 -1131CC carriers than in TC and CC carriers, but also suggests that identification of carriers of the $\mathrm{C}$ allele of the APOA5-1131 polymorphism may be helpful for preventive care for MS. In addition, the percentage of participants with one or more MS risk factors suggests that subjects harboring the APOA5 $-1131 \mathrm{CC}$ genotype are potentially at risk for developing MS (Supplementary Figure 1).

\section{Conclusions}

In conclusion, the present study describes that the APOA5 $-1131 \mathrm{~T}>\mathrm{C}$ polymorphism is significantly associated with 
serum HDL-C and TG levels, as well as with MS risk, because of its pronounced effect on serum TG levels in Korean subjects. Therefore, we believe that the identification of carriers of the minor allele of the APOA5 $-1131 \mathrm{~T}>\mathrm{C}$ polymorphism may prove helpful in predicting MS susceptibility and overall risk assessment for metabolic diseases such as cardiovascular disease. Additional studies, including not only other sequence variants of APOA5 but also a large number of uninvestigated single nucleotide polymorphismMS associations via genome-wide association studies, will further enhance the validity of associations and the causative relationships between the genetic variants and MS.

\section{Authors' Contributions}

S. Cha and S.-G. Yu contributed equally to this work.

\section{Acknowledgment}

This work was supported by the National Research Foundation of Korea (NRF) Grant funded by the Korea government (MEST) (no. 20120009001 (2006-2005173)). The authors have declared that they have no conflict of interest.

\section{References}

[1] R. H. Eckel, S. M. Grundy, and P. Z. Zimmet, "The metabolic syndrome," The Lancet, vol. 365, no. 9468, pp. 1415-1428, 2005.

[2] E. Expert Panel on Detection, and Treatment of High Blood Cholesterol in Adults, "Executive summary of the third report of the national cholesterol education program (NCEP) expert panel on detection, evaluation, and treatment of high blood cholesterol in adults (adult treatment panel III)," The Journal of the American Medical Association, vol. 285, no. 19, pp. 2486-2497, 2001.

[3] S. Lim, H. Shin, J. H. Song et al., "Increasing prevalence of metabolic syndrome in Korea: the Korean national health and nutrition examination survey for 1998-2007," Diabetes Care, vol. 34, no. 6, pp. 1323-1328.

[4] L. Groop, "Genetics of the metabolic syndrome," British Journal of Nutrition, vol. 83, supplement 1, pp. S39-S48, 2000.

[5] T. Joy and R. A. Hegele, "Genetics of metabolic syndrome: is there a role for phenomics?" Current Atherosclerosis Reports, vol. 10, no. 3, pp. 201-208, 2008.

[6] C. M. Povel, J. M. Boer, E. Reiling et al., "Genetic variants and the metabolic syndrome: a systematic review," Obesity Reviews, vol. 12, no. 11, pp. 952-967, 2011.

[7] A. H. Kissebah, G. E. Sonnenberg, J. Myklebust et al., "Quantitative trait loci on chromosomes 3 and 17 influence phenotypes of the metabolic syndrome," Proceedings of the National Academy of Sciences of the United States of America, vol. 97, no. 26, pp. 14478-14483, 2000.

[8] S. Francke, M. Manraj, C. Lacquemant et al., "A genome-wide scan for coronary heart disease suggests in Indo-Mauritians a susceptibility locus on chromosome $16 \mathrm{p} 13$ and replicates linkage with the metabolic syndrome on 3q27," Human Molecular Genetics, vol. 10, no. 24, pp. 2751-2765, 2001.

[9] C. D. Langefeld, L. E. Wagenknecht, J. I. Rotter et al., "Linkage of the metabolic syndrome to 1q23-q31 in hispanic families: the insulin resistance atherosclerosis study family study," Diabetes, vol. 53, no. 4, pp. 1170-1174, 2004.

[10] A. T. Kraja, D. Vaidya, J. S. Pankow et al., "A bivariate genome-wide approach to metabolic syndrome: STAMPEED consortium," Diabetes, vol. 60, no. 4, pp. 1329-1339, 2011.

[11] L. A. Pennacchio, M. Olivier, J. A. Hubacek et al., "An apolipoprotein influencing triglycerides in humans and mice revealed by comparative sequencing," Science, vol. 294, no. 5540, pp. 169-173, 2001.

[12] P. J. Talmud, E. Hawe, S. Martin et al., "Relative contribution of variation within the APOC3/A4/A5 gene cluster in determining plasma triglycerides," Human Molecular Genetics, vol. 11, no. 24, pp. 3039-3046, 2002.

[13] J. T. Kao, H. C. Wen, K. L. Chien, H. C. Hsu, and S. W. Lin, "A novel genetic variant in the apolipoprotein A5 gene is associated with hypertriglyceridemia," Human Molecular Genetics, vol. 12, no. 19, pp. 2533-2539, 2003.

[14] T. Nabika, S. Nasreen, S. Kobayashi, and J. Masuda, "The genetic effect of the apoprotein AV gene on the serum triglyceride level in Japanese," Atherosclerosis, vol. 165, no. 2, pp. 201-204, 2002.

[15] L. Baum, B. Tomlinson, and G. N. Thomas, "APOA5-1131T>C polymorphism is associated with triglyceride levels in Chinese men," Clinical Genetics, vol. 63, no. 5, pp. 377-379, 2003.

[16] B. E. Aouizerat, M. Kulkarni, D. Heilbron et al., "Genetic analysis of a polymorphism in the human apoA-V gene: effect on plasma lipids," Journal of Lipid Research, vol. 44, no. 6, pp. 1167-1173, 2003.

[17] T. Zhao and J. Zhao, "Association of the apolipoprotein A5 gene $-1131 \mathrm{~T}>\mathrm{C}$ polymorphism with fasting blood lipids: a metaanalysis in 37859 subjects," BMC Medical Genetics, vol. 11, no. 1, article 120, 2010.

[18] A. Maasz, P. Kisfali, K. Horvatovich et al., "Apolipoprotein A5 T$1131 \mathrm{C}$ variant confers risk for metabolic syndrome," Pathology and Oncology Research, vol. 13, no. 3, pp. 243-247, 2007.

[19] Y. Yamada, K. Kato, T. Hibino et al., "Prediction of genetic risk for metabolic syndrome," Atherosclerosis, vol. 191, no. 2, pp. 298-304, 2007.

[20] L. A. Hsu, Y. L. Ko, C. J. Chang et al., "Apolipoprotein A5 gene $-1131 \mathrm{~T} / \mathrm{C}$ polymorphism is associated with the risk of metabolic syndrome in ethnic Chinese in Taiwan," Clinical Chemistry and Laboratory Medicine, vol. 46, no. 12, pp. 1714-1719, 2008.

[21] H. Grallert, E. M. Sedlmeier, C. Huth et al., "APOA5 variants and metabolic syndrome in Caucasians," Journal of Lipid Research, vol. 48, no. 12, pp. 2614-2621, 2007.

[22] E. Komurcu-Bayrak, A. Onat, M. Poda et al., "Gendermodulated impact of apolipoprotein A5 gene (APOA5) $-1131 \mathrm{~T}>\mathrm{C}$ and $\mathrm{c} .56 \mathrm{C}>\mathrm{G}$ polymorphisms on lipids, dyslipidemia and metabolic syndrome in Turkish adults," Clinical Chemistry and Laboratory Medicine, vol. 46, no. 6, pp. 778-784, 2008.

[23] K. H. Song, S. G. Yu, S. Cha, and J. Y. Kim, "Association of the apolipoprotein A5 gene $-1131 \mathrm{~T}>\mathrm{C}$ polymorphism with serum lipids in Korean subjects: impact of Sasang constitution," Evidence-Based Complementary and Alternative Medicine, vol. 2012, Article ID 598394, 8 pages, 2012.

[24] S. Jeong, H. Yu, Y. Lee, and J. Y. Kim, "SNP genotyping through the melting analysis of unlabelled oligonucleotide applied on dilute PCR amplicon," Journal of Biotechnology, vol. 154, no. 4, pp. 321-325, 2011. 
[25] A. D. Association, "Diagnosis and classification of diabetes mellitus," Diabetes Care, vol. 29, supplement 1, pp. S43-S48, 2006.

[26] WHO/IASO/IOTF, The Asia-Pacific Perspective: Redefining Obesity and Its Treatment, Health Communications, Melbourne, Australia, 2000.

[27] C. Q. Jiang, T. H. Lam, B. Liu et al., "Interleukin-6 receptor gene polymorphism modulates interleukin- 6 levels and the metabolic syndrome: GBCS-CVD," Obesity, vol. 18, no. 10, pp. 1969-1974, 2010.

[28] N. Sarwar, M. S. Sandhu, S. L. Ricketts et al., "Triglyceridemediated pathways and coronary disease: collaborative analysis of 101 studies," The Lancet, vol. 375, no. 9726, pp. 1634-1639, 2010.

[29] C. P. Oliva, F. Carubbi, F. G. Schaap, S. Bertolini, and S. Calandra, "Hypertriglyceridaemia and low plasma HDL in a patient with apolipoprotein A-V deficiency due to a novel mutation in the APOA5 gene," Journal of Internal Medicine, vol. 263, no. 4, pp. 450-458, 2008.

[30] Y. Jang, J. Y. Kim, O. Y. Kim et al., "The $-1131 \mathrm{~T} \rightarrow \mathrm{C}$ polymorphism in the apolipoprotein A5 gene is associated with postprandial hypertriacylglycerolemia; elevated small, dense LDL concentrations; and oxidative stress in nonobese Korean men," American Journal of Clinical Nutrition, vol. 80, no. 4, pp. 832-840, 2004.

[31] K. H. Lee, O. Y. Kim, H. H. Lim, Y. J. Lee, Y. Jang, and J. H. Lee, "Contribution of APOA5-1131C allele to the increased susceptibility of diabetes mellitus in association with higher triglyceride in Korean women," Metabolism, vol. 59, no. 11, pp. 1583-1590, 2010. 

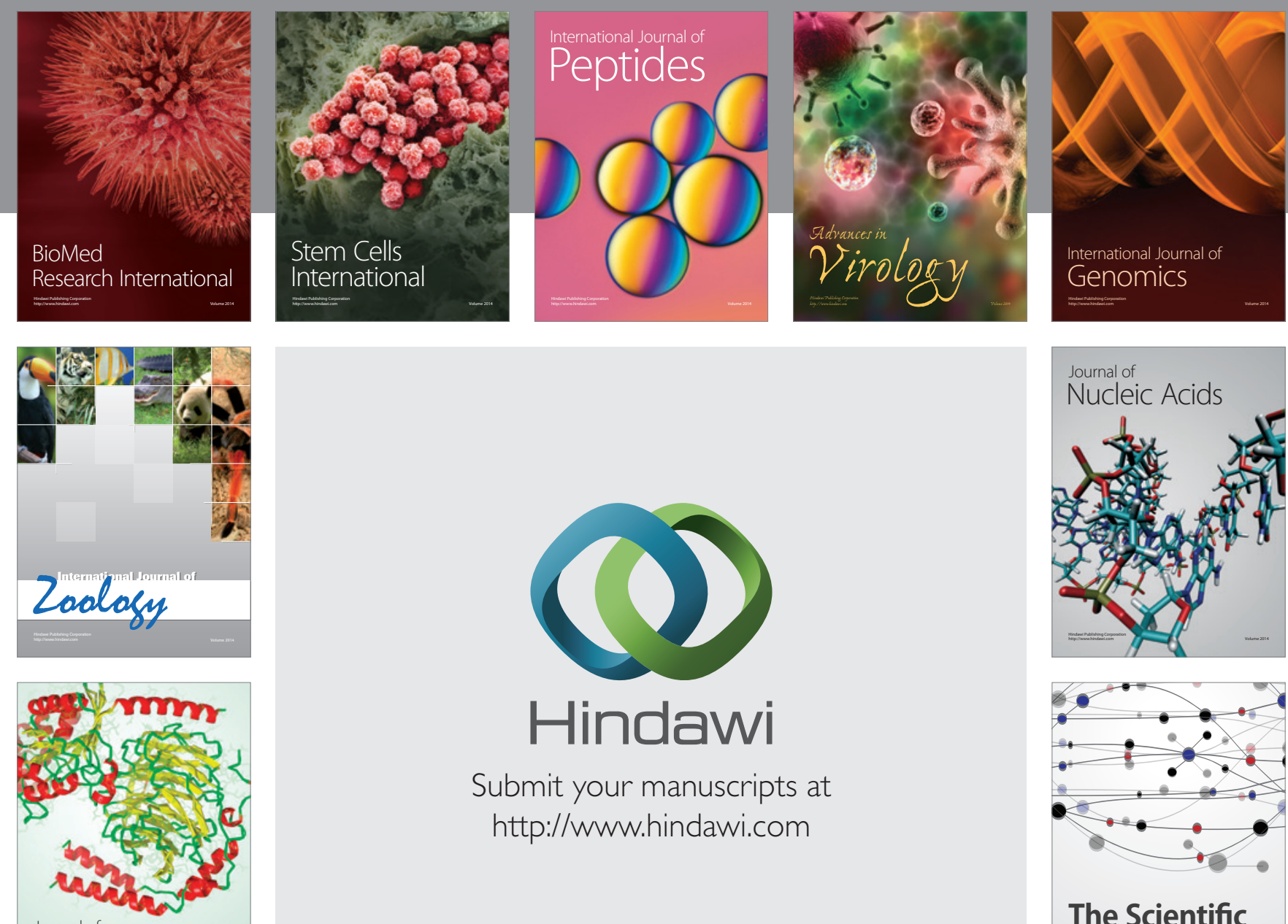

Submit your manuscripts at

http://www.hindawi.com

Journal of
Signal Transduction
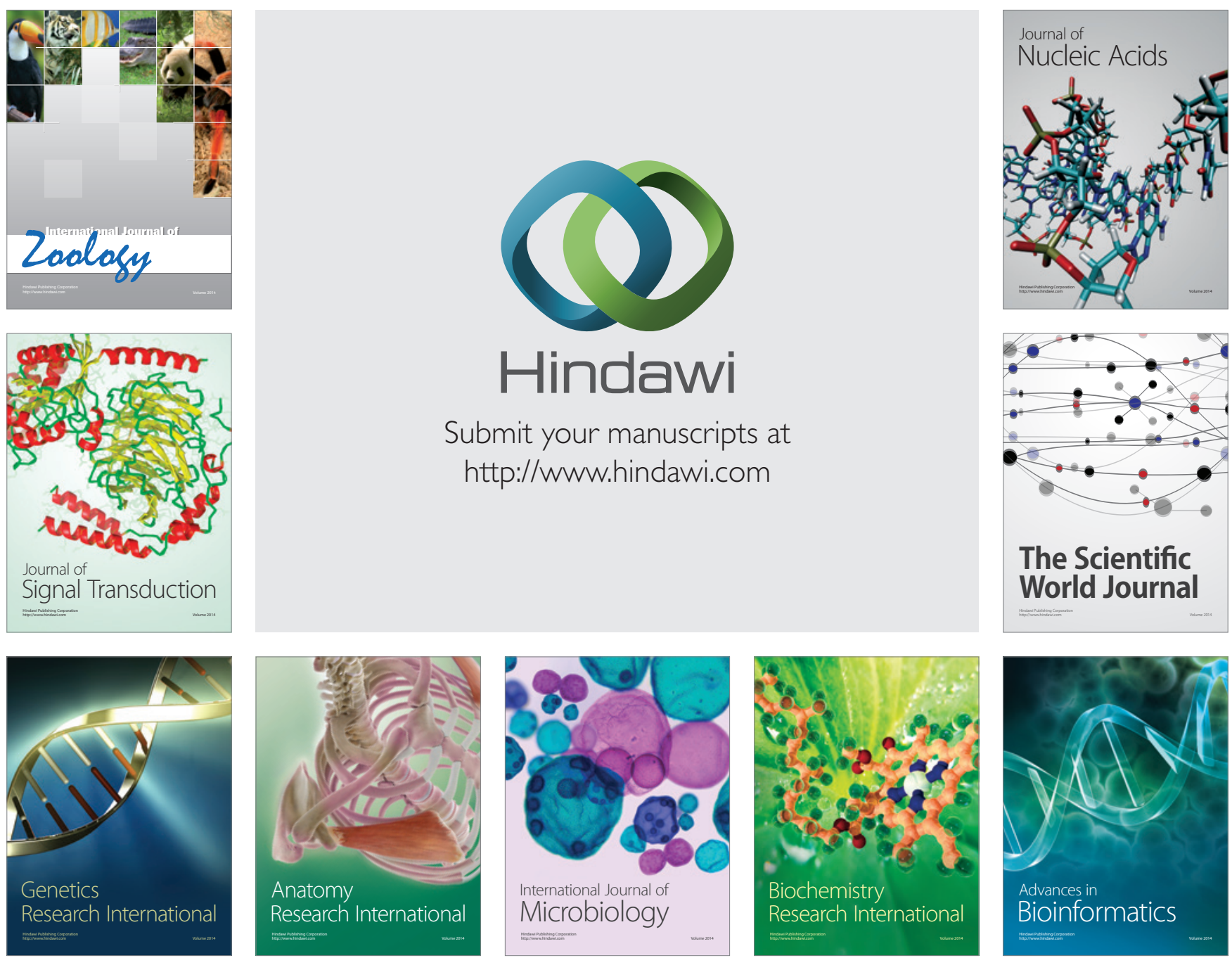

The Scientific World Journal
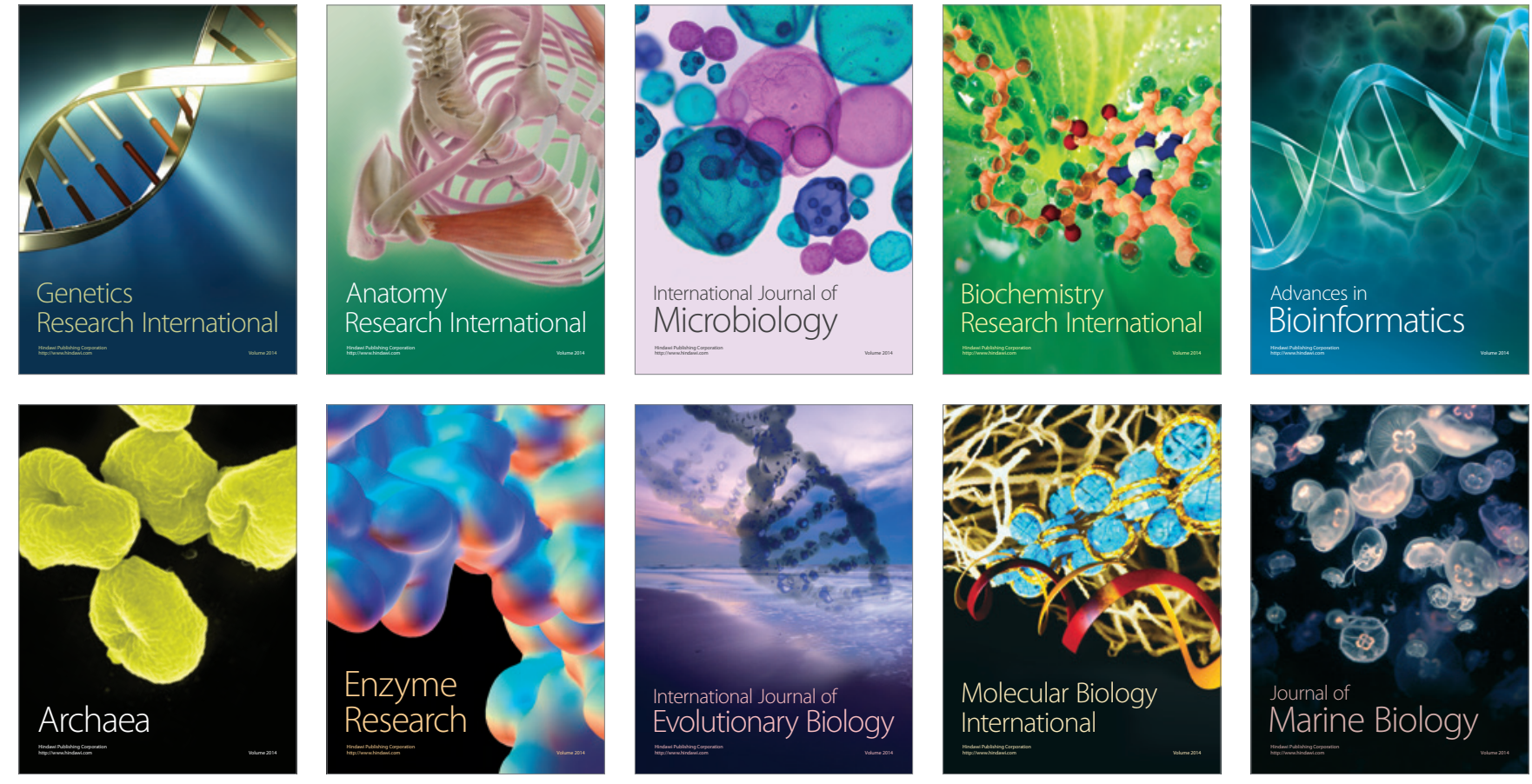